\title{
Workshop Penggunaan Microsoft Office Sebagai Penunjang Keterampilan Hard Skill Siswa Pendidikan Dasar
}

\author{
Hari Prasetijo1, Ari Fadli, ${ }^{* 2}$, Purwanto Bekti Santoso³ ${ }^{3}$ Widhiatmoko Herry Purnomo \\ 1,2,4Teknik Elektro, Universitas Jenderal Soedirman \\ ${ }^{3}$ Teknik Sipil, Universitas Jenderal Soedirman \\ *e-mail: arifadli@unsoed.ac.id $^{2}$
}

\begin{abstract}
Abstrak
Dusun Siwarak Kulon merupakan salah satu desa yang ada di Desa Watuagung yang terletak di ketinggian 200- 250 MDPL di kawasan hutan pinus Perum Perhutani Kesatuan Pemangkuan Hutan (KPH) Banyumas. Di sini terdapat sebuah Sekolah Dasar yang ketersediaan fasilitas pendukung pendidikan formal dan kegiatan ekstra yang terbatas. Kemampuan pada penggunaan Microsoft Office merupakan salah satu faktor yang dapat menunjang pendidikan formal, oleh karena itu kegiatan workshop penggunaan Microsoft Office untuk pendidikan dasar sangat dibutuhkan. Kegiatan ini bertujuan memberikan edukasi tentang penggunaan Microsoft Office. Kegiatan ini dilaksanakan dengan metode presentasi materi dan praktik sederhana. Hasil worskhop menunjukan nilai rata-rata pre test peserta adalah 37.39, sedangkan nilai ratarata post test peserta adalah 72.60. Hasil tersebut menunjukan bahwa kegiatan workshop menunjukan adanya dampak peningkatan dalam pemahaman dan ketrampilan peserta dalam penggunaan komputer dan pengoperasian aplikasi Microsft Office.
\end{abstract}

Kata kunci: Workshop, Microsoft Office, Pendidikan Formal

\begin{abstract}
Dusun Siwarak Kulon is one of the villages in Watuagung Village, which is located at an altitude of 200-250 MDPL in the pine forest area of Perum Perhutani Kesatuan Pemangkuan Hutan (KPH) Banyumas. Here there is an elementary school which has limited facilities for supporting formal education and extra activities. The ability to use Microsoft Office is one of the factors that can support formal education, therefore workshop activities on using Microsoft Office for basic education are needed. This activity aims to provide education about the use of Microsoft Office. This activity is carried out with the method of material presentation and simple practice. The results of the workshop showed the pre-test mean score of the participants was 37.39, while the participants' average post-test score was 72.60 . These results indicate that the workshop activities show an impact on the increase in the understanding and skills of participants in using computers and operating Microsft Office applications.
\end{abstract}

Keywords: Workshop, Microsoft Office, Formal Education

\section{PENDAHULUAN}

Penguasaan ilmu pengetahuan dan teknologi tidak hanya dilakukan pada pendidikan formal, namun dilakukan pula melalui pendidikan nonformal. Selain itu, dengan perkembangan dan kemajuan teknologi, mampu membantu menghasilkan informasi yang mempunyai nilai lebih jika dibandingkan dengan cara manual [1]. Menurut Undang-Undang No.20 Tahun 2003 Tentang Sistem Pendidikan Nasional dijelaskan pada Pasal 26 ayat 3. Dalam pasal tersebut dikatakan bahwa Pendidikan nonformal meliputi pendidikan kecakapan hidup, pendidikan anak usia dini, pendidikan kepemudaan, pendidikan pemberdayaan perempuan, pendidikan keaksaraan, pendidikan keterampilan dan pelatihan kerja, pendidikan kesetaraan, serta pendidikan lain yang ditujukan untuk mengembangkan kemampuan peserta didik.

Hal mengenai pendidikan dan pelatihan kerja diperjelas pada ayat 5 yang berbunyi bahwa Kursus dan pelatihan diselenggarakan bagi masyarakat yang memerlukan bekal pengetahuan, keterampilan, kecakapan hidup, dan sikap untuk mengembangkan profesi, bekerja, usaha mandiri, atau melanjutkan pendidikan kejenjang yang lebih tinggi. Salah satu jenis pelatihan yang dimaksud adalah pelatihan keterampilan komputer. Pelatihan keterampilan komputer adalah serangkaian kegiatan yang memberikan kesempatan untuk mendapatkan dan meningkatkan keterampilan yang berkaitan dengan komputer [2]. Contoh penerapan pelatihan komputer yang 
pernah dilakukan adalah pelatihan komputer ini adalah workshop praktis bagi para pemuda dan perangkat Desa Blater agar memiliki skill merakit dan memelihara Personal Computer (PC) [3]. Era Revolusi Industri 4.0 keterampilan akan penguasaan bidang teknologi informasi dan komunikasi sangat diperlukan. Microsoft Word dan Microsoft Excel adalah salah satu program pengolah kata dan pengolah informasi yang dimasukkan dalam bandle Microsoft Office.

Microsoft Excel diberbagai kebutuhan sering digunakan seperti menyusun laporan keuangan [4], pelatihan dalam pengelolaan data dan penyusunan laporan keuangan [5][6]. Microsoft Excel merupakan program aplikasi lembar kerja yang memiliki fungsi untuk mengolah data seperti perhitungan, rumus, pemakaian fungsi, tabel, pembuatan grafik dan manajemen data [7]. Microsoft Excel merupakan salah satu program spreadsheet terpopuler dan tercanggih saat ini. Excel banyak berperan dalam pengelolaan informasi, khususnya data yang berbentuk angka untuk perhitungan. Berbagai fungsi dan fasilitas yang dimiliki Excel memungkinkan untuk olah data dalam berbagai kasus, baik dalam perusahaan dagang, jasa, maupun perusahaan Industri [8].

Microsoft Word memiliki beberapa versi sejak kelahirannya di tahun 1983. Beberapa versi memang didesain untuk sistem operasi Windows yaitu Microsof Word 97, Microsoft Word 2000, Microsoft Word XP, Microsoft Word 2003, Microsoft Word 2007, Microsoft Word 2010, dan Microsoft Word 2013. Kesemuanya memiliki kelebihan berdasar pengembangan versi sebelumnya. Fungsi utama dari Microsoft Word adalah sebagai software/program pengolah kata bagi user [9].

Dusun Siwarak Kulon merupakan merupakan perbukitan pada ketinggian 200-250 Mdpl di kawasan hutan pinus Perum Perhutani Kesatuan Pemangkuan Hutan (KPH) Banyumas Timur dengan jarak $8 \mathrm{~km}$ dari pusat desa Watuagung kecamatan Tambak kabupaten Banyumas Jawa Tengah. Jumlah penduduk di Dusun Siwarak Kulon adalah \pm 400 jiwa dengan 100 kepala keluarga dengan mata pencaharian petani ladang/hutan, pembuat gula kelapa, dan buruh dalam kategori ekonomi rendah. Di sini terdapat satu SD Negeri yang belum dilengkapi perangkat komputer untuk melengkapi kegiatan ekstra kelas.

Secara umum akses penggunaan komputer diperoleh dari aktivitas pendidikan di tingkat SMP di pusat desa Watuagung. Kondisi tersebut menjadi faktor utama kelangkaan kesempatan bagi anak usia pendidikan dasar di dusun ini untuk mendapatkan akses pengetahuan dan ketrampilan komputer dari dini. Kegiatan pengabdian kepada masyarakat yang dilakukan oleh tim pengabdian kepada masyarakat Fakultas Teknik Unsoed dilaksanakan pada bulan Juni sampai dengan September 2019. Kegiatan Pengabdian Kepada Masyarakat ini merupakan bentuk solusi yang ditawarkan dalam bentuk memberikan fasilitas komputer dan workshop penggunaan program Microsoft Word dan Microsoft Excel bagi anak usia pendidikan dasar sebagai bekal keterampilan akan penguasaan bidang teknologi informasi dan komunikasi Pada era Revolusi Industri 4.0 .

\section{METODE}

\section{A. Khalayak Sasaran}

Tuntutan akan kemampuan penggunaan Teknologi Informasi Sejak dini guna menghadapi era Revolusi Industri 4.0 Serta Minimnya Fasilitas Pendidikan Bidang TIK di Dusun Siwarak Kulon Kabupaten Banyumas maka Khayalak sasaran pada kegiatan pengabdian masyarakat ini adalah siswa usia pendidikan dasar yang ada di Dusun Siwarak Kulon Kabupaten Banyumas.

\section{B. Tahapan Pelaksanaan Kegiatan}

Dalam pelaksanaan kegiatan ini dibagi menjadi dua bagian yaitu :

\section{Pemaparan Materi}

Metode ini akan memberikan pengetahuan umum dan teori - teori praktis yang perlu dipahami dalam menggunakan atau menjalankan aplikasi Microsoft Word dan Microsoft Excel.

\section{Workshop}

Metode ini akan memberikan kemampuan teknis dalam aplikasi Microsoft Word dan Microsoft Excel. Pada aplikasi Microsoft Word peserta dilatih untuk dapat membuat tulisan, membuat tabel, memasukan gambar dan mencetak dokumen. Sedangkan pada Microsoft Excel, 
peserta workshop dilatih untuk membuat perhitungan-perhitungan dasar (perkalian, pembagian, penjumlahan, dan pengurangan).

3. Menjawab Pertanyaan Kuesioner

Metode ini akan menilai kemampuan peserta sebelum dan setelah mengikuti kegiatan workshop.

\section{Evaluasi Keberhasilan}

Keberhasilan pelaksanaan pogram pengabdian masyarakat ini dilihat dari dua tolok ukur sebagai berikut :

1. Respons positif dari peserta pelatihan Respons peserta pelatihan akan diukur melalui observasi selama pelatihan berlangsung berdasarkan jumlah peserta dan rasa antusiasme peserta workshop.

2. Meningkatnya keterampilan peserta setelah mendapat pelatihan Keterampilan peserta pelatihan akan diobservasi saat pelatihan melalui pemberian tugas-tugas contoh latihan selama pelatihan dan selama proses pendampingan

\section{HASIL DAN PEMBAHASAN}

Kontribusi mendasar yang ingin dicapai pada kegiatan PKM ini kepada khalayak sasaran yaitu meningkatnya pengetahuan, ketrampilan dalam penggunaaan program komputer berupa Microsoft Word dan Microsoft Excel.

\section{A. Lokasi Pelaksaan Kegiatan}

Lokasi pelaksanaan Kegiatan Pengabdian Kepada Masyarakat bertempat di mushola Al Huda yang berada di dusun Siwarak Kulon. Pemilihan Mushola Al Huda sebagai lokasi kegiatan pengabdian ini dikarenakan mushola Al Huda yang merupakan satu-satunya wadah aktivitas pendidikan non formal yaitu kegiatan Taman Pendidikan Al Quran (TPQ) yang rutin dilaksanakan 2 hari dalam satu minggu dirasa cocok oleh tim pengabdi untuk dijadikan tempat dilaksanakan kegiatan pengabdian kepada masyarakat.

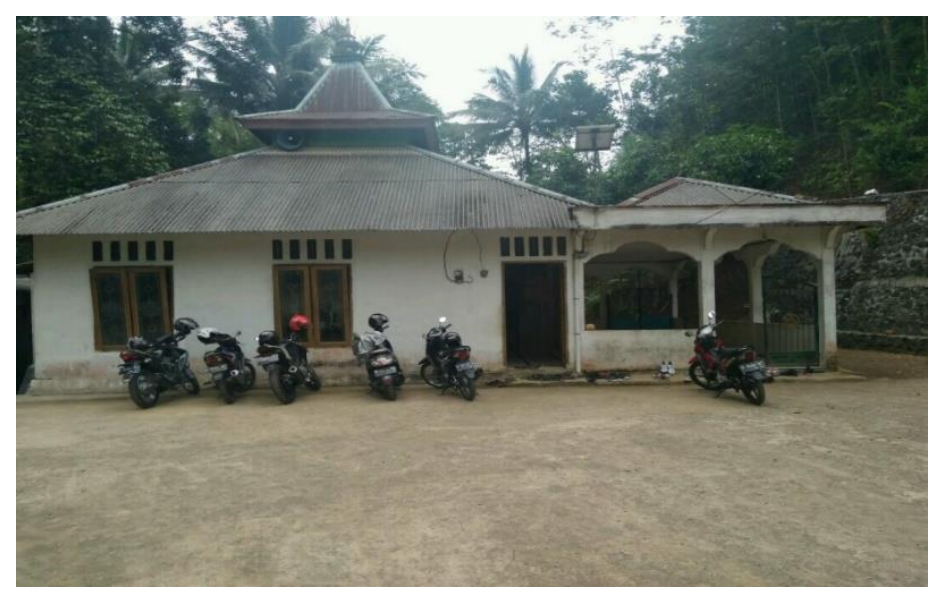

Gambar 1. Lokasi Pelaksanaan Kegiatan

Aktivitas program kegiatan masyarakat berupa workshop pelatihan word dan excel yang akan dilakukan oleh tim pengusul akan diintegrasikan dengan aktivitas TPQ tersebut agar terjamin implementasinya serta diharapkan dapat meningkatkan kualitas dan efektivitas pendidikan non formal tersebut.

Selain hal tersebut, Mushola Al Huda ini terdapat sumber energi listrik yang berasal dari pembangkit listrik piko hidro yang merupakan hasil program pengabdian masyarakat tim 
pengusul pada tahun 2017 untuk penerangan yang akan ditingkatkan pemanfaatannya sebagai sumber energi listrik untuk fasilitas pelatihan komputer.

\section{B. Sambutan}

Pada Gambar 2 Pelaksanaan Kegiatan ini dimulai dengan pemberian arahan oleh Hari Prasetijo, S.T., M.T., sebagai ketua pelaksana kegiatan pengabdian kepada masyarakat.

\section{Pemaparan Materi}

Pada sesi pemaparan materi seperti tampak pada Gambar 3 dan Gambar 4, dilakukan secara berkelompok. Pengelompokan peserta kegiatan pelatihan program komputer microsoft word dan excel ini didasarkan pada usia perserta yang relatif beragam yaitu mulai dari pendidikan dasar hingga pendidikan menengah pertama. Setiap kelompok tersebut didampingi oleh seorang pendamping yang berasal dari tim pengabdi dan warga setempat yang sebelumnya telah di latih.

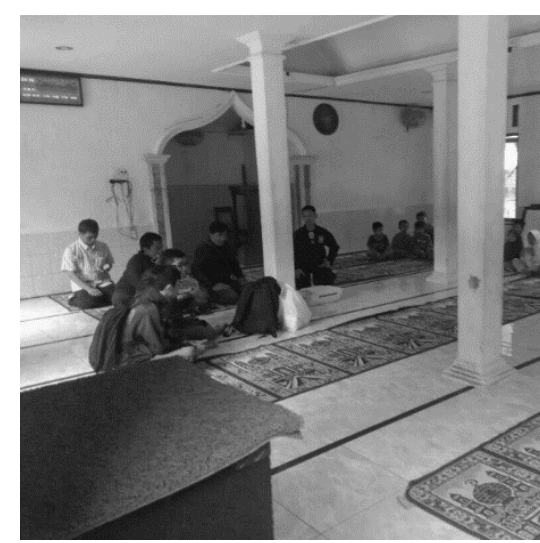

(a)

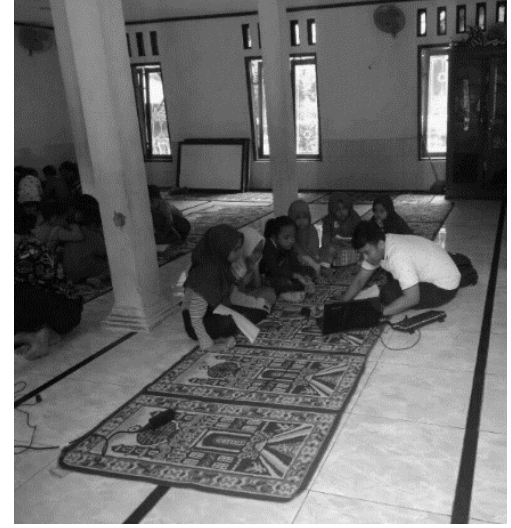

(b)

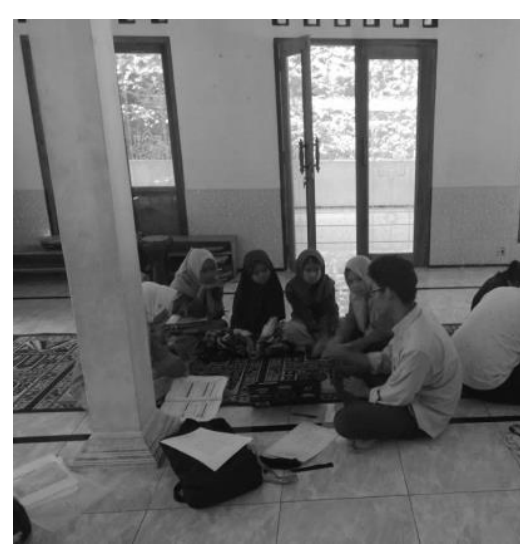

(c)

Gambar 2. (a) Sambutan Ketua Pelaksana (b) Suasana 1 Pemaparan Materi

(c) Suasana 2 Pemaparan Materi

Setiap peserta yang mengikuti kegiatan pelatihan mendapatkan pengetahuan yang sama, namun dengan tingkat kesulitan dan kedalaman materi yang disesuaikan dengan kelompok dimana perserta tersebut berada. Pada sesi pemaparan materi ini disampaikan materi dasar terkait penggunaan aplikasi microsoft word dan microsoft excel. Dengan outline materi yang disampaikan yaitu :

1. Pengenalan Word Dan Excel

2. Membuat, Menyimpan Dan Membuka File

3. Pengaturan Dasar Word

4. Memasukan Gambar serta Membuat Diagram

5. Membuat dan Mengkreasikan Tabel

6. Menghitung Dengan Excel

\section{Workshop}

Setelah peserta mendapatkan pengetahuan pada sesi pemaparan materi yang dilakukan sebelumnya, maka setiap peserta disetiap kelompok akan diberi tugas oleh masing-masing pendamping kelompoknya. Beberapa Tugas yang diberikan kepada setiap peserta tersebut, tampak pada Gambar berikut :

1. Membuat dan Memodifikasi Tabel di microsoft word, dengan menggunakan layout tabel seperti tampak pada Gambar 3. 


\begin{tabular}{|l|l|l|l|}
\multicolumn{1}{c|}{ Hari } & \multicolumn{1}{c|}{ Andi } & Bayu & Kemal \\
\hline Senin & Sapu & & \\
\hline Selasa & Ngepel & & \\
\hline Rabu & Lap Kaca & & \\
\hline Kamis & Lap Meja & \\
\hline
\end{tabular}

Gambar 3. Membuat dan memodifikasi tabel di microsoft word

2. Membuat tulisan dan kemudian memodifikasinya, dengan bentuk tulisan tampak pada Gambar 3.

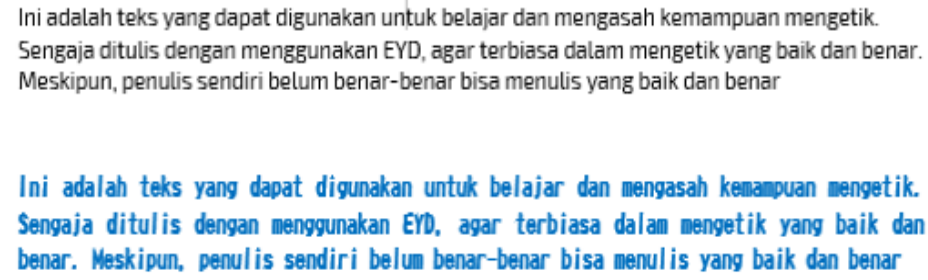

Ini adalah teks yang dapat digunakan untuk belajar dan mengasah kemampuan mengetik. Sengaja ditulis dengan menggunakan EYD, agar terbiasa dalam mengetik yang baik dan benar. Meskipun, penul is sendiri belum benar-benar bisa menul is yang baik dan benar

Gambar 3. Materi membuat dan memodifikasi tulisan

3. Memasukan gambar yang ada di komputer kedalam microsoft word, seperti tampak ada Gambar 4.

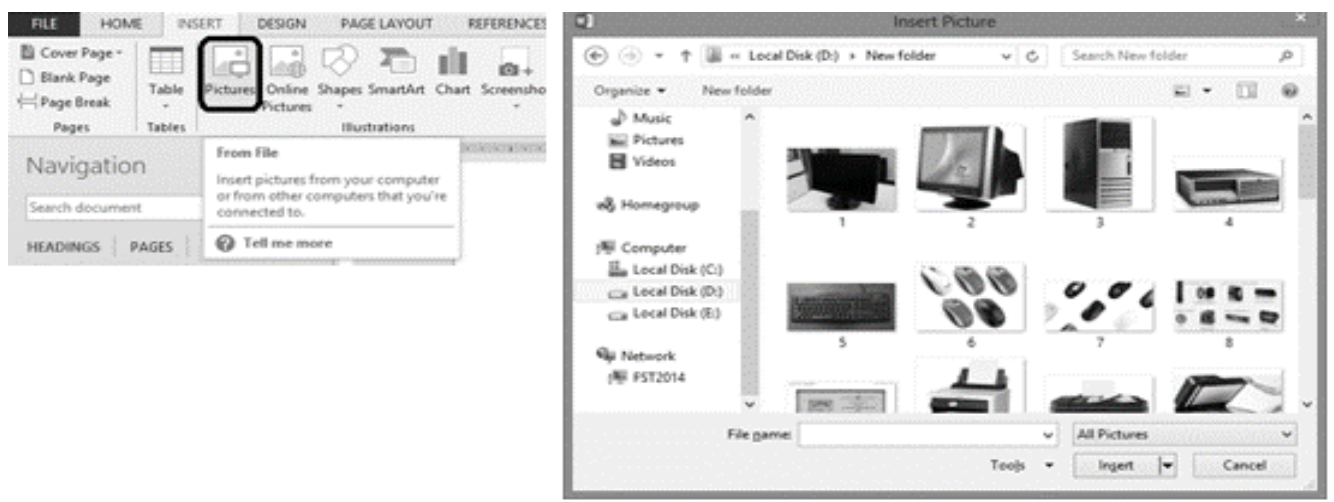

Gambar 4. Memasukan gambar

4. Melakukan perhitungan dengan menggunakan microsoft excel, perhitungan yang dilakukan dengan menggunakan microsoft excel ini tampak pada Gambar 6.

\begin{tabular}{|c|l|c|c|c|}
\hline No & Buah & Banyak & Terjual & Sisa \\
\hline 1 & Apel & 130 & 90 & \\
\hline 2 & Jeruk & 120 & 70 & \\
\hline 3 & Pepaya & 100 & 60 & \\
\hline 4 & Nanas & 70 & 50 & \\
\hline 5 & Durian & 80 & 30 & \\
\hline
\end{tabular}

(a)

\begin{tabular}{|c|l|c|c|c|}
\hline No & Buah & Banyak & Harga per kg & Harga Total \\
\hline 1 & Apel & 130 & 100 & \\
\hline 2 & Jeruk & 120 & 200 & \\
\hline 3 & Pepaya & 100 & 150 & \\
\hline 4 & Nanas & 70 & 40 & \\
\hline 5 & Durian & 80 & 20 & \\
\hline
\end{tabular}

(b)

Gambar 6. Melakukan perhitungan sederhana dengan excel

5. Mencetak salah satu dokumen tugas dengan menggunakan printer yang telah disediakan oleh tim pengabdi.

Setiap peserta diwajibkan menyelesaikan setiap tugas yang diberikan tersebut. Dikarenakan akan diukur kemampuan keterampilannya sebelum dan setelah mengikuti workshop. Suasana workshop tampak seperti pada Gambar 7. 


\section{E. Antusiasme Peserta dan Evaluasi dengan Kuesioner}

Evaluasi antusiasme peserta dilihat berdasarkan jumlah peserta yang ikut dalam kegiatan workshop ini, dengan jumlah peserta yang mengikuti kegiatan ini adalah 22, kegiatan ini cukup sukses dan menarik.

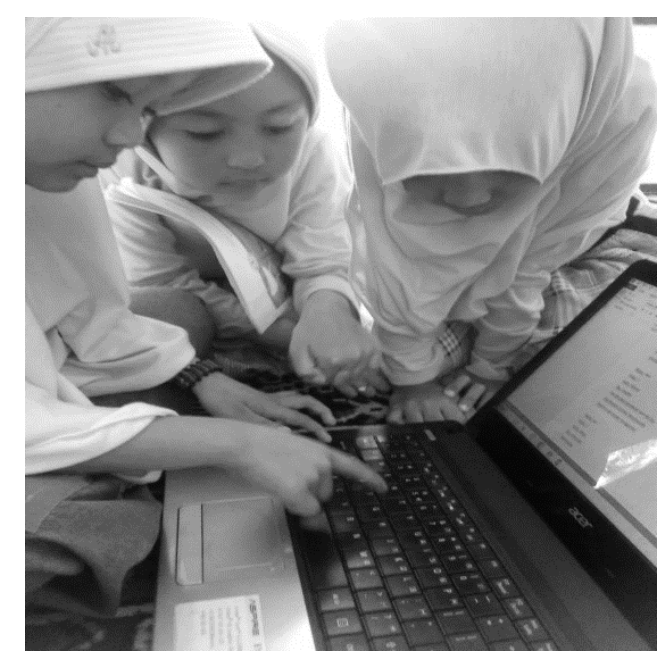

(a)

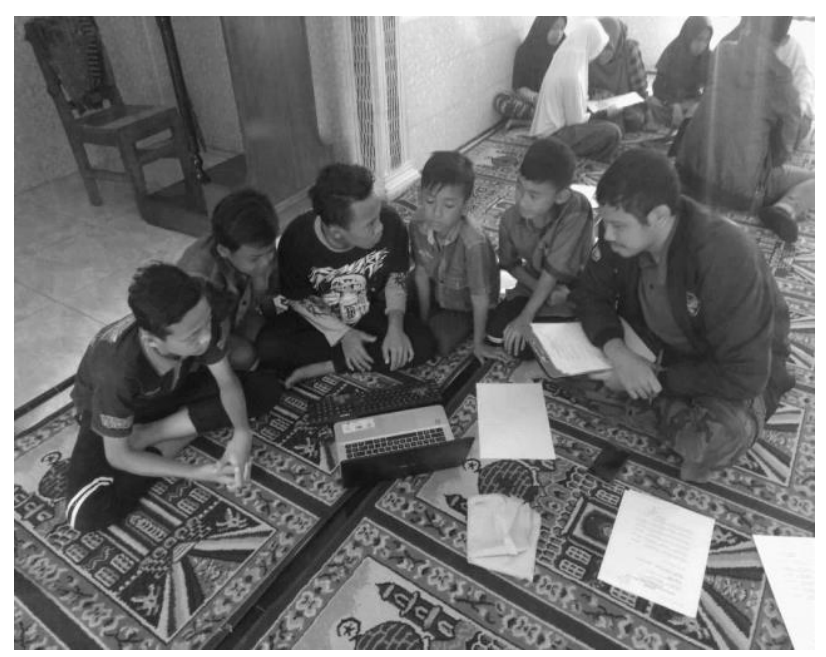

(b)

Gambar 7. Suasana kegiatan workshop

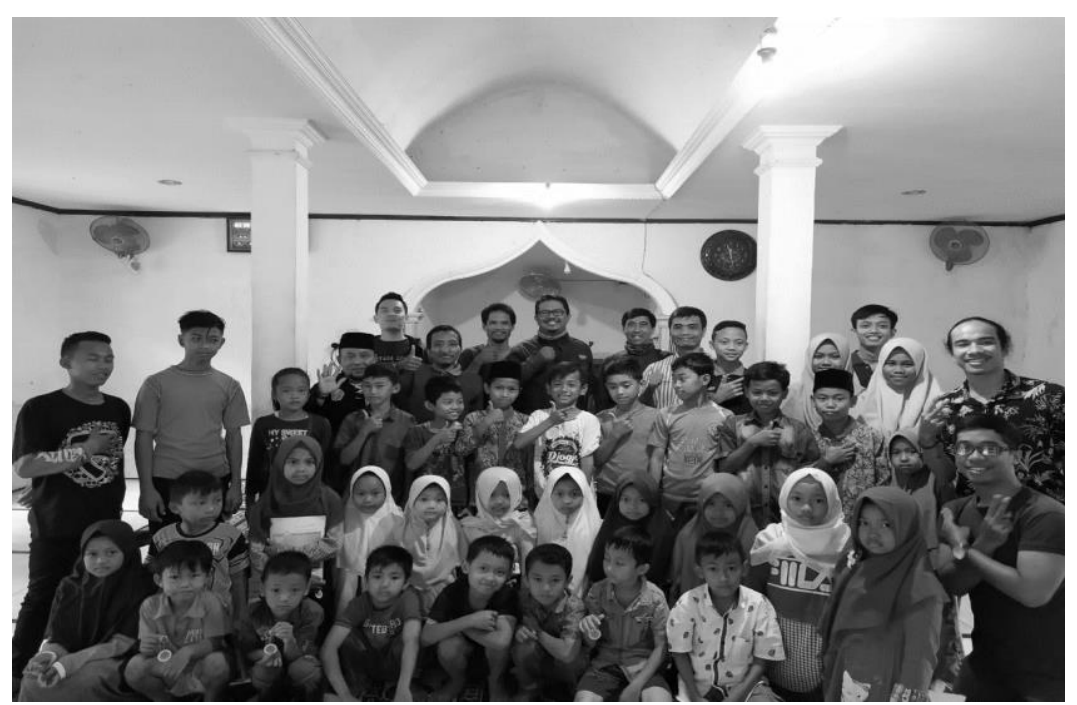

Gambar 8. Peserta kegiatan workshop

Sebagai salah satu bentuk tolak ukur keberhasilan pendamping kelompok dalam menyampaian materi serta tingkat pemahaman para peserta, maka dalam kegiatan pengabdian ini dilaksanakan tahapan ujian kepada setiap peseta yang dilakukan sebelum (pretest) dan setelah (post test) pemaparan materi dan kegiatan workshop.

Daftar pertanyaan yang digunakan dalam ujian tersebut yaitu

1. Apakah sudah pernah menggunakan perangkat komputer?

2. Jika sudah pernah Kapan terakhir menggunakan?

3. Aplikasi word digunakan untuk ?

4. Aplikasi excel digunakan untuk ?

5. Praktik membuat bagaimana cara membuat tulisan di word ?
(a) Sangat Terampil
(b) Terampil 

(c) Cukup Terampil
(d) Belum Bisa

6. Praktik membuat bagaimana cara membuat tabel di word ?
(a) Sangat Terampil
(b) Terampil
(c) Cukup Terampil
(d) Belum Bisa

7. Praktik membuat bagaimana membuat penomoran di word ?
(a) Sangat Terampil
(b) Terampil
(c) Cukup Terampil
(d) Belum Bisa

8. Praktik membuat bagaimana cara memasukan gambar di word ?
(a) Sangat Terampil
(b) Terampil
(c) Cukup Terampil
(d) Belum Bisa

9. Praktik membuat penjumlahan, pengurangan, perkalian dan pembagian di excel ?
(a) Sangat Terampil
(b) Terampil
(c) Cukup Terampil
(d) Belum Bisa

10. Praktik mencetak dokumen dengan menggunakan printer
(a) Sangat Terampil
(b) Terampil
(c) Cukup Terampil
(d) Belum Bisa

Hasil yang diperoleh dari ujian yang diberikan kepada setiap peserta workshop tampak pada Tabel 1 dan Tabel 2. Berdasarkan hasil yang diperoleh tersebut sebagaimana pada Tabel 1 dan Tabel 2 tampak bahwa perolehan nilai rata-rata yang meningkat. Namun jika dilihat nilai tersebut secara mandiri, ada beberapa peserta workshop yang memiliki nilai baik saat pretest dan posttest, hal ini disebabkan karena sebelum kegiatan pengabdian ini dilaksanakan peserta tersebut telah mendapatkan materi serupa di tempat peserta bersekolah.

Tabel 1. Hasil Pre Test (Rata-rata 37.39)

\begin{tabular}{cccc}
\hline Peserta & Post Test & Peserta & Post Test \\
\hline 1 & 80 & 12 & 10 \\
2 & 10 & 13 & 70 \\
3 & 10 & 14 & 60 \\
4 & 10 & 15 & 50 \\
5 & 10 & 16 & 50 \\
6 & 10 & 17 & 60 \\
7 & 80 & 18 & 60 \\
8 & 10 & 19 & 50 \\
9 & 10 & 20 & 50 \\
10 & 10 & 21 & 40 \\
11 & 30 & 22 & 10 \\
\hline
\end{tabular}


Tabel 2. Hasil Post Test (Rata-rata 72.60)

\begin{tabular}{cccc}
\hline Peserta & Post Test & Peserta & Post Test \\
\hline 1 & 80 & 12 & 80 \\
2 & 60 & 13 & 80 \\
3 & 60 & 14 & 80 \\
4 & 50 & 15 & 80 \\
5 & 60 & 16 & 80 \\
6 & 50 & 17 & 80 \\
7 & 80 & 18 & 90 \\
8 & 80 & 19 & 100 \\
9 & 60 & 20 & 80 \\
10 & 50 & 21 & 80 \\
11 & 50 & 22 & 80 \\
\hline
\end{tabular}

Selain itu, walaupun terjadi peningkatan pemahaman materi secara keseluruhan, aspek waktu pengerjaan tugas yang masih menjadi pekerjaan rumah bersama, karena rata-rata peserta kegiatan workshop masih membutuhkan waktu yang relatif lama untuk mengerjakan setiap tugas yang diberikan oleh setiap pendamping kelompok Excel.

\section{KESIMPULAN}

Berdasarkan pada hasil kegiatan pengabdian kepada masyarakat berupa pelatihan program komputer Microsoft Word dan Microsoft Excel yang dilakukan di dusun Siwarak Kulon masih ditemukannya kendala yaitu tingkat waktu pengerjaan peserta pada setiap tugas yang diberikan pendamping pada workshop. Sehingga dengan hal ini perlu dilakukannya keberlanjutan atas kegiatan ini. Dengan melibatkan warga setempat sebagai pendamping maka harapan tim pengabdi adalah warga setempat dapat membantu keberlanjutan kegiatan ini dengan peserta didik yang baru

\section{UCAPAN TERIMA KASIH}

Penghargaan dan ucapan terimakasih kami sampaikan kepada pihak Lembaga Penelitian dan Pengabdian kepada Masyarakat (LPPM) Universitas Jenderal Soedirman, yang telah memberikan dukungan dana sehingga Program Pengabdian kepada Masyarakat : PKM Peningkatan Pemanfaatan Pembangkit Listrik Piko Hidro Untuk Pelatihan Ketrampilan Komputer Bagi Anak Usia Pendidikan Dasar

\section{DAFTAR PUSTAKA}

[1] M. M. Gultom and Maryam, "SISTEM INFORMASI PENJUALAN MATERIAL BANGUNAN PADA TOKO BANGUNAN BERKAH", J. Tek. Inform. (JUTIF), vol. 1, no. 2, pp. 79-86, Dec. 2020.

[2] I Made Agus Wirawan, Dessy Seri Wahyuni, and Ida Bagus Made Ludy Paryatna. 2015. Laporan Kemajuan Pengabdian Kepada Masyarakat Undhiksa Pelatihan Microsoft Office Untuk Guru - Guru SeKecamatan Susut.

[3] Zulfa, Mulki Indana, Ari Fadli, Daru Tri Nugroho, and Arief Wisnu Wardhana. 2018. "Workshop Merakit Dan Memelihara Personal Komputer Dalam Peninngkatan Pengetahuan Dan Keterampilan Bagi Karang Taruna Dan Perangkat Desa Blater Purbalingga." : 226-34.

[4] Fajrinshanty, I., Herawati, N. T., \& Atmadja, A. T. 2019. "Penerapan Standar Akuntasi Keuangan Entitas Tanpa Akuntabilitas Publik (Sak Etap) Pada Ud Sinar Abadi. Jimat." Jurnal Ilmiah Mahasiswa Akuntansi) Undiksha 8(2): 2019.

[5] Mulyani, Y. S., Wibisono, T., Alawiyah, T., \& Warnilah, A. I. 2019. "Pelatihan Komputer Dasar Untuk Mendukung Proses Kegiatan Belajar Mengajar ( KBM ) Bagi Guru-Guru RA / TPQ / DTA Al-Ishlaah Kota Tasikmalaya." Jurnal Abdimas BSI 2(2): 234-240.

[6] Arsi, P., Pambudi, A. S., \& Maisa, W. 2019. "Peningkatan Kualitas SDM Dengan Pemanfaatan Iptek 
Melalui Pelatihan Komputer Dasar Dan Internet Pada Anggota Polsek Kedungbanteng." Jurnal Abdimas BSI 2(2): 191-196.

[7] Abdullah, D., Millenia, D., Nusfiana, D., Ariance, E., \& Krisnawati, F. (2. 2019. "Persamaan Dan Perbedaan Microsoft Excel. INA-Rxiv , 2016 - 2018." : 2019.

[8] Nurcholisah, Kania, Helliana, Nurhayati, and Nunung Nurhayati. 2011. "Penggunaan Program Excel Untuk Meningkatkan Kualitas Proses Belajar Mengajar Pada Mata Kuliah Pengantar Akuntansi." Prosiding Seminar Nasional Penelitian dan PKM: Sosial, Ekonomi, dan Humaniora 2(1): 401-10.

[9] Ikhwani, Yusri, Haldi Budiman, and Muhammad Rasyidan. 2015. "Pelatihan Aplikasi Microsoft Word 2013 Pada SMP H. A. Johansyah. A Banjarmasin." Jurnal Al-Ikhlas 1(1): 11-14. 